\title{
Integralidade do Cuidado: representações sociais das equipes de Saúde da Família do Distrito Federal
}

\section{Comprehensive Care: social representations of Family Health teams in Distrito Federal, Brazil}

\author{
Vladimir Andrei Rodrigues Arce \\ Doutorando em Saúde Coletiva pelo Instituto de Saúde Coletiva da \\ Universidade Federal da Bahia. Professor Assistente da Universida- \\ de Federal da Bahia. Instituto de Ciências da Saúde. Departamento \\ de Fonoaudiologia, \\ Endereço: Avenida Reitor Miguel Calmon, sn, Vale do Canela, CEP \\ 40110-100, Salvador, Bahia, Brasil. \\ E-mail: vladimir.arceळufba.br \\ Maria Fátima de Sousa \\ Doutora em Ciências da Saúde. Professora Adjunta da Universidade \\ de Brasília. Departamento de Saúde Coletiva e da Faculdade de \\ Ciências da Saúde, Universidade de Brasília. \\ Endereço: Faculdade de Ciências da Saúde- FS/UnB. Campus Uni- \\ versitário Darcy Ribeiro, Universidade de Brasília. CEP 70910-900, \\ Brasília, DF, Brasil. \\ E-mail: mariafatimasousa®uol.com.br
}

\section{Resumo}

Trata-se de pesquisa qualitativa que analisou as representações sociais dos profissionais da Estratégia Saúde da Família (ESF) do Distrito Federal-DF acerca da integralidade do cuidado. A ESF vem sendo implantada no Brasil desde 1994 como uma estratégia política para reordenar o modelo de atenção à saúde, estando atualmente em processo de ampliação no DF. Foram realizados entrevistas individuais semiestruturadas e grupo focal com gestores locais e profissionais das equipes de 11 das 15 regionais de saúde. Utilizou-se o Discurso de Sujeito Coletivo (DSC) e a teoria das Representações Sociais para análise, com o objetivo de compreender a sociogênese da forma de pensar a partir de um olhar psicossocial sobre a realidade. Verificou-se que o cuidado é percebido como ato de solidariedade e atributo profissional, apoio às famílias em suas múltiplas necessidades e articulação de ações interdisciplinares de prevenção, promoção e tratamento, visando qualidade de vida. A integralidade do cuidado permeia a noção de autonomia profissional, requer a criação de vínculos de confiança e responsabilização entre profissionais e usuários, a contextualização da família sobre os determinantes e formas de enfrentamento dos problemas e demanda a integração com demais serviços. 0 estudo demonstrou que o cuidado relaciona-se com diferentes dimensões da integralidade, refletindo potencialidades e desafios do modelo da ESF para o desenvolvimento de práticas ampliadas de saúde. Faz-se necessário que a potencialidade das relações estabelecidas entre diferentes sujeitos no território permita a qualificação das ações de saúde, sobretudo aquelas voltadas para a promoção.

Palavras-chave: Estratégia Saúde da Família; Integralidade; Cuidado. 


\section{Abstract}

This qualitative research analyzed the social representations about comprehensive care of the health professionals who work at the teams of the Family Health Strategy (ESF) in Distrito Federal - DF, Brazil. The ESF is being implemented in Brazil since 1994 as a political strategy in order to reorganize the "model of health care", and currently is in expansion in the DF. The study was developed in 11 of 15 health regions in DF; information was gathered through individual semi-structured interviews and focal group with local managers and teams' professionals. Interviews were analyzed using the Discourse of the Collective Subject (DSC) method based on the theory of Social Representations, aiming to understand the sociogenesis of thinking, taking into account the psychosocial reality. It was found that care is understood both as an act of solidarity and a professional attribute to support families in their multiple needs; it is seen as an articulation of interdisciplinary activities of prevention, health promotion and treatment, aiming to improve quality of life. Comprehensive care permeates the idea of professional autonomy, whaicht requires bonds of trust and accountability between professionals and patients, contextualizing the families about health determinants and forms of facing problems and, finally, integration among care providers. entering service health s are seen as by the professionalswhich consider health there is a for health. The study showed that the care is related to different dimensions of comprehensiveness, reflecting the potential and challenges of the ESF model for the development of expanded health care practices. The potential of relationships established among different subjects in the territory must allow that professional actions become more qualified, particularly those related to health promotion. potential of the relations established allows the health

Keywords: Family Health Strategy; Comprehensiveness; Care.

\section{Introdução}

Este artigo apresenta uma síntese dos resultados e discussões alcançados em pesquisa sobre a integralidade do cuidado à saúde no âmbito da Atenção Primária junto às equipes da Estratégia Saúde da Família (ESF) das diferentes regionais de saúde que integram o Sistema Único de Saúde (SUS) no Distrito Federal (DF).

Para tanto, concebe Atenção Primária enquanto nível do sistema de saúde responsável pela entrada de todas as novas necessidades e problemas da população e pela organização de um sistema de saúde integrado, apresentando funções exclusivas no âmbito do sistema de saúde, bem como atributos próprios, como a atenção ao primeiro contato, a longitudinalidade, a coordenação do cuidado e a integralidade (Starfield, 2004). Portanto, a Atenção Primária integra um processo permanente de assistência sanitária, que inclui prevenção, promoção, cura e reabilitação, envolvendo outros setores para promover o desenvolvimento social e enfrentar os determinantes da saúde, reorientando o modelo assistencial com garantia de atenção integral (Starfield, 2004; Giovanella, 2008), o que expressa a importância da integralidade enquanto eixo central deste nível de atenção.

No Brasil, a ESF surge como principal estratégia política para a reorientação do modelo de atenção à saúde, fundamentando-se em uma nova ética social e cultural com vistas à promoção da saúde e da qualidade de vida dos indivíduos, famílias e comunidades (Sousa, 2008). Além disso, apresenta como ponto central o vínculo e a criação de laços de compromisso entre profissionais e população: a equipe deve entender a família a partir do ambiente em que vive e constrói suas relações, buscando constantemente garantir a proteção social por meio da universalidade e integralidade (Brasil, 2007; Mendonça e col., 2008). Isto demanda uma ampliação da concepção de cuidado em relação ao processo saúde-doença.

Estas questões evidenciam as perspectivas micro e macropolítica da ação em saúde inscritas na proposta da ESF, que, enquanto estratégia de reorientação do modelo de atenção assume o cuidado como principal propósito do sistema de. Assim, 
passa a demandar tanto um novo saber quanto um novo saber-fazer que dialoguem com as diferentes dimensões da integralidade, de forma a orientar novas práticas de saúde que reflitam positivamente sobre as necessidades locais. Correlacionando-se cuidado, enquanto propósito das práticas de saúde, e integralidade, enquanto princípio orientador, busca-se garantir a integralidade do cuidado na Atenção Primária, o que representa um importante desafio especificamente para os profissionais que atuam diretamente nas equipes de Saúde da Família, demandando a condução permanente de pesquisas sobre o tema.

As práticas de saúde dos profissionais são permeadas pelas representações que estes têm acerca da integralidade do cuidado: estas evidenciam um amplo espectro de subjetividades e saberes que não raramente fundamentam e determinam o cotidiano de seus processos de trabalho. Acessar e compreender tais representações permite identificar lacunas a serem enfrentadas pelo desencadeamento de novos processos de formação em saúde; além disso, a partir deste conhecimento pode-se forjar novas abordagens que permitam o fortalecimento da integralidade do cuidado nas realidades locais das equipes.

Assim, o objetivo deste artigo é apresentar e discutir as representações de integralidade do cuidado expressas por profissionais que compõem as equipes de Saúde da Família do Distrito Federal.

\section{Integralidade(s): assumindo o cuidado como eixo da Estratégia} Saúde da Família

Na literatura, a integralidade pode ser observada em relação às práticas, aos serviços e às políticas, conforme afirma Mattos (2009). Ela relaciona-se transversalmente com a noção de cuidado e compõe suas diversas dimensões no campo da saúde. Dar-se-á ênfase neste artigo à relação que se estabelece entre a integralidade e o cuidado, perspectiva apontada como possível e necessária por diversos autores, buscando articular tal relação às representações dos profissionais das equipes da ESF. Assume-se, desta forma, o entendimento de que só é possível garantir a integralidade do cuidado a partir do reconhecimento da multidimensionalidade envolvida nos processos de cuidado no âmbito da Saúde da Família, que deve ser explicitamente concretizada no cotidiano do trabalho dos profissionais da saúde.

Mattos (2009) discorre sobre três principais sentidos do termo integralidade no âmbito da saúde. Em relação à dimensão das práticas, este autor considera que são configuradas socialmente e afirma que os profissionais da saúde devem compreender e atender a um conjunto de necessidades que a população apresenta e não apenas àquelas diretamente ligadas às doenças. Mattos afirma ainda que a integralidade deve ser um valor sustentado e defendido nas práticas dos profissionais, expressando a forma como estes respondem aos usuários. Portanto, relaciona-se a uma atitude voltada para a boa prática profissional, que não se reduz à prevenção e ao controle das doenças.

Considerando a integralidade dos serviços, o autor critica a dissociação entre práticas de saúde pública e práticas assistenciais que podem ser observadas em modelos tradicionais de atenção à saúde. Para ele, a integralidade deixa de ser uma atitude profissional e passa a ser um modo de organizar o processo de trabalho em equipe, que deve produzir impacto positivo sobre a saúde da população, mas não unicamente por meio da assistência médica. Portanto, uma forma horizontal de programar os serviços de saúde deve ser concebida, utilizando-se da epidemiologia, mas não só dela, para estabelecer respostas mais adequadas às necessidades da população, associando demanda espontânea e programada.

Mattos (2009) destaca ainda a dimensão política da integralidade, na medida em que a define como bandeira de luta e imagem-objetivo da configuração de um sistema considerado desejável por diferentes atores numa arena política: ela exprime um conjunto de valores que se relacionam a um ideal de sociedade mais justa e solidária. Ele postula que a integralidade representa uma recusa em reduzir a objetos descontextualizados os sujeitos sobre os quais as políticas incidem, ampliando o horizonte de problemas a serem tratados por estas políticas e respeitando as especificidades de diferentes grupos populacionais, garantindo tanto ações de prevenção quanto assistenciais. 
Observa-se que as dimensões da integralidade apontadas por Mattos (2009) possuem semelhanças e pontos de articulação que implicam em uma recusa ao reducionismo em todos os níveis, seja a partir da abertura para o diálogo, numa necessária relação sujeito-sujeito no campo das práticas e dos serviços de saúde, seja a partir de um processo de luta, que exprime as diferentes relações de poder que existem numa arena política e que influenciam o processo do cuidado.

Considerando este espectro de dimensões no âmbito da saúde, verifica-se a relação da integralidade com o propósito do cuidado e suas implicações na conformação das práticas dos profissionais da Estratégia Saúde da Família.

Refletindo sobre o cuidado humano e as práticas de saúde, Maia e Vaghetti (2008) consideram que a experiência de ser, existir e viver em um mundo contraditório e em transformação revela alguns pressupostos da essência do cuidado, tais como a relação intrínseca com os processos histórico-sociais. Ele é uma expressão da humanidade, um processo contínuo de sensibilidade, troca e atitude, sobretudo ética, de viver em sintonia consigo e com os outros. Assim, o viver em sociedade influencia as escolhas e as decisões, estando o cuidado fundamentado no diálogo e no pacto com a diversidade social, cultural, entre outras. Tais pressupostos contribuem para a conformação das práticas de saúde em diferentes contextos, tais como o da Atenção Primária.

Merhy (200o) aponta que a dimensão do cuidado está diretamente ligada a uma relação de acolhimento e vínculo que permite, por meio de processos de fala e escuta, a relação do profissional com o mundo subjetivo do usuário e o modo como ele constrói suas necessidades. Assim, diferentes saberes podem ser articulados na elaboração e condução de projetos terapêuticos. Para o autor, a produção do cuidado ocorre no espaço relacional entre profissional e usuário no qual são produzidos os atos de saúde; isto dá característica singular ao processo de trabalho em saúde, e está sob influência direta do capital financeiro, que passa a não colocar a defesa da vida individual e coletiva como finalidade do campo da saúde.

Para Ayres (200o), a dimensão do cuidado, ao se preocupar com a promoção do bem-estar para além da correção de distúrbios, permite que as diferentes aspirações por saúde de indivíduos e populações sejam inseridas na assistência, uma vez que quando o indivíduo se apresenta como portador de um problema, ele se coloca como aspirante ao bem-estar, e assim, a maneira como compreende suas próprias necessidades deve ser necessariamente considerada. . Para tal, deve-se estabelecer uma abertura na relação terapêutica: o profissional, sujeito cuidador, participa do momento assistencial demandando arranjos tecnológicos mais sensíveis às necessidades de saúde, num processo de reconstrução de intersubjetividades apoiado na tecnologia, mas sem deixar que a intervenção em saúde se resuma a ela.

Cuidar da saúde, portanto, passa pelas competências e tarefas técnicas mas não se restringe a elas, pois significa mais que tratar, curar ou controlar. Logo, é mais que construir um objeto abstrato a partir de uma visão única e intervir sobre ele, pois há que se considerar os diferentes projetos de vida envolvidos, bem como construir projetos mútuos no encontro de diferentes sujeitos, o que desconstrói a perspectiva fragmentária das práticas de saúde a partir da expansão da atitude cuidadora para as reflexões e intervenções no campo da saúde durante o encontro de sujeitos (Ayres, 2001).

Já na perspectiva da integralidade, a noção de cuidado não é entendida como um nível de atenção do sistema de saúde ou como algum procedimento técnico específico, mas como uma ação integral, que tem significados e sentidos voltados para a compreensão da saúde como o direito de ser, que concebe o sofrimento como fruto da fragilidade social (Pinheiro e Guizardi, 2008).

Pinho e colaboradores (2007) apontam que a integralidade se configura como dimensão teóricoprática do saber em saúde coletiva, que vai da perspectiva macroestrutural à subjetiva. Esta última é construída nas relações com os sujeitos que são atendidos nos serviços de saúde, relacionando-se à compreensão da natureza do ser por inteiro e à perspectiva de redimensionamento dos serviços para sustentar a saúde como uma proposta a ser construída na relação intersubjetiva, da qual fazem parte o acolhimento e o vínculo.

Ademais, o propósito da integralidade do cuidado imprime aos profissionais a tarefa de perceberem o usuário como sujeito histórico, social e político, 
articulado ao contexto familiar, ao meio ambiente e à sociedade na qual se insere. Assim, faz com que estes profissionais incorporem diferentes ações de saúde ao cotidiano do trabalho, a exemplo das ações de educação em saúde, na perspectiva de se produzir conhecimento coletivo capaz de fomentar a autonomia e a emancipação do indivíduo para o cuidar de si, de sua família e de seu entorno (Machado e col., 2007). A partir desta visão abrangente, afirmar a integralidade do cuidado no âmbito da saúde demanda a revisão das práticas sanitárias e dos processos de trabalho historicamente desenvolvidos nos serviços de saúde (Pinheiro e Guizardi, 2008).

Desta forma, observa-se que o cuidado, objetivo dos sistemas de saúde, relaciona-se com as dimensões política, dos serviços e das práticas que compõem a integralidade no âmbito da saúde, permitindo a identificação de zonas de contato ou de complementaridade para a conformação das práticas dos profissionais. Tal relação evidencia, portanto, a integralidade do cuidado como um importante atributo a ser buscado na Atenção Primária e, consequentemente, na ESF.

\section{Percursos da Investigação}

O Distrito Federal possui uma população de aproximadamente 2.600.00o habitantes. Arede de serviços da Secretaria de Estado de Saúde é estruturada em 15 Regionais de Saúde, nas quais existem 15 hospitais regionais e 03 hospitais especializados (que disponibilizam 4.164 leitos gerais e 315 leitos de Unidade de Terapia Intensiva), 61 Centros de Saúde, 76 Unidades Básicas de Saúde da Família, oı Policlínica, o3 Unidades Mistas, o1 Instituto de Saúde Mental e 1.36o consultórios ambulatoriais (Distrito Federal, 2011). O complexo regulador desta rede é composto por Central de Marcação de Consultas e Exames, Central de Regulação de Internação Hospitalar e Central Estadual de Regulação da Alta Complexidade Interestadual (Distrito Federal, 2007).

Na Atenção Primária do DF coexistem dois modelos de atenção: o "modelo convencional”, organizado por meio dos Centros de Saúde e especialidades ambulatoriais, e o modelo da Estratégia Saúde da Família, que em fevereiro de 2011 apresentava 113 equipes completas, com cobertura de $15 \%$ da popu- lação. Além disso, há 13 Núcleos de Apoio à Saúde da Família, 10 equipes de Atenção Domiciliar e 11 de Saúde Prisional, todos ligados à Subsecretaria de Atenção Primária à Saúde da Secretaria de Estado de Saúde do DF (SAPS/SESDF). Para esta pesquisa, definiu-se como objeto de análise a ESF.

Este estudo de natureza qualitativa tem como cenário de pesquisa a ESF no Distrito Federal e como base teórico-metodológica a Teoria das Representações Sociais. Segundo Santos (2009), esta teoria permite ao pesquisador compreender a sociogênese da forma de pensar, do senso comum, pois traz a ideia de indissociabilidade entre o sujeito e a sociedade: a partir de um olhar psicossocial sobre a realidade, considera-se o sujeito como ativo, construtor e construído nesta realidade social, que se constitui nas relações com o outro em um dado contexto social e em um momento histórico preciso.

São sujeitos da pesquisa profissionais e gestores locais das equipes de Saúde da Família. Ressalta-se que todos os sujeitos possuem vínculo público com a Administração Direta, trabalhando de acordo com o regime estatutário. Os critérios de inclusão foram: indicação dos gestores regionais de equipes com profissionais considerados informantes-chave para o objeto da pesquisa; equipes consistidas no Sistema de Cadastro Nacional de Estabelecimentos de Saúde - SCNES há pelo menos um ano com os mesmos profissionais considerando a data da coleta de dados. Selecionou-se uma equipe por regional de Saúde do DF e foram realizadas entrevistas semi-estruturadas com profissionais de 11 equipes de Saúde da Família, sendo um por regional, totalizando 11 sujeitos três médicas, duas enfermeiras, três auxiliares de enfermagem e três agentes comunitários de saúde, definidos por regional de maneira aleatória.

Também foi realizado um grupo focal com os coordenadores das 11 equipes, que contou com a adesão de sete sujeitos. De forma a complementar os dados, realizou-se observação direta sistematizada do processo de trabalho desenvolvido em um período de quatro horas de cada equipe nos dias em que foram realizadas as entrevistas com os profissionais.

As entrevistas foram agendadas por telefone, sendo realizadas nos diferentes locais de trabalho dos profissionais. 0 grupo focal foi realizado em sala isolada no Núcleo de Estudos de Saúde Pública da 
Universidade de Brasília - NESP/UnB. O material foi gravado e transcrito para análise posterior, etapa na qual foi utilizada a técnica do Discurso do Sujeito Coletivo (Lefévre e Lefévre, 2003). Os dados qualitativos obtidos são tabulados e organizados em um discurso síntese, redigido na primeira pessoa do singular e elaborado com extratos de depoimentos de sentido significativo semelhante.

Para a apresentação dos resultados, utilizou-se das Expressões-chave e das Ideias Centrais das falas que permitiram a construção do Discurso do Sujeito Coletivo (DSC). Todos os sujeitos participantes assinaram o Termo de Consentimento Livre e Esclarecido em duas vias, de acordo com o projeto aprovado pelo Comitê de Ética em Pesquisa da Secretaria de Estado de Saúde do DF, sob o protocolo número 229/10.

Os resultados e as discussões apresentados a seguir foram provocados por duas questões norteadoras da pesquisa, a saber: 1) Fale um pouco sobre o que representa para você cuidar da saúde das famílias; 2) $E$ em relação à integralidade do cuidado, como é isso pra você? A partir destas questões, foram encontradas e discutidas diferentes categorias genuínas de Ideias Centrais relacionadas às representações dos sujeitos das equipes. Optou-se por discutir inicialmente as representações de cuidado e, posteriormente, de integralidade do cuidado.

\section{Resultados e Discussão}

\section{O cuidado como ato de solidariedade a partir de um processo de identificação subjetiva ou atributo pessoal do profissional}

Percebe-se que a representação de cuidado dos sujeitos entrevistados é perpassada pela ideia de solidariedade em relação ao outro, no caso o usuário ou a família, retratando, portanto, uma postura acolhedora vislumbrada pela própria equipe. Para tanto, demanda-se do profissional algum nível de sensibilidade e de identificação com os problemas das pessoas, o que permite a expressão de sua subjetividade, conforme pode ser observado no fragmento abaixo:

É muito gratificante... eu cuido das famílias, das pessoas, como se fosse um parente meu, um familiar meu... é uma preocupação mesmo com o bem-estar de cada um. $\varepsilon$ algo assim que realmente eu faço com muito carinho, com muito amor, eu me identifico muito. Principalmente com a gestante, porque eu casei recentemente e minha esposa tá gestante, e eu tenho um cuidado maior por causa disso, entendeu?

No entanto, embora seja possível reconhecer uma postura acolhedora do profissional em relação ao usuário, esta não garante a expressão de uma relação de troca, de produção de intersubjetividades, e desta forma, não é suficiente para que o cuidado extrapole a dimensão técnica e profissional.

O cuidar, conforme demonstrado, não depende unicamente da capacidade técnica do profissional de saúde, podendo ser estabelecido num processo relacional, corroborando Merhy (200o) e Ayres (200o). Entretanto, a partir do fragmento do discurso apresentado, identifica-se a necessidade do reconhecimento, por parte da equipe, do outro como sujeito autônomo da atenção e do cuidado à saúde, sendo este o grande desafio para a integralidade apontado por Costa (2004) e, portanto, um desafio para a própria ESF.

De todo modo, esta representação de cuidado potencializa a ESF em seu propósito de transformar o modelo assistencial praticado na Atenção Primária a partir da criação de laços e vínculos da equipe com as pessoas, o que pode ser observado no discurso. A responsabilização demonstrada dos profissionais pelos problemas das famílias permite a aproximação com uma ideia de proteção e de busca de bem-estar, que só é possível quando se concebe e se pratica a saúde de uma maneira ampla, para além do serviço. Pode-se dizer que uma nova ética social e cultural (Sousa, 2008) é, deste modo, vivenciada, acrescentando-se a esta constatação dados oriundos da observação realizada nas unidades, que demonstram a preocupação dos profissionais com aspectos da vida pessoal dos usuários, abordando-os na rua quando passam em frente às unidades mesmo que não estejam buscando o serviço de saúde.

\section{Cuidado como apoio às famílias em suas múltiplas necessidades e características (aspectos biológi- cos, mentais e sociais)}

Nesta categoria, observa-se que cuidar da saúde das famílias demanda um conhecimento sobre o 
contexto familiar e social dos usuários, e para tanto os profissionais devem se inserir no cotidiano das comunidades, percebendo as relações que são estabelecidas no território, e não apenas as identificadas dentro do serviço de saúde.

Estar mais próximo daquele paciente, ter um contato direto com as pessoas e aívocê passa a conhecer a realidade dele. Não só ficar dentro do posto, pois assim você não tem uma visão ampla. Conforme seja a situação dessa família, a gente pode mudar, a gente pode reorganizar essa família de diversos sentidos... até mesmo na harmonia, na convivência, na saúde, no modo de vida, de pensar e até na prosperidade dessa família. Não é só o medicar, é o ouvir, o escutar... o aconselhar, o compartilhar, o acompanhar... esse é o grande lance do Saúde da Família. Não é só a doença em si, mas éo bem-estar físico, mental e social. Algumas pessoas querem mesmo nem tanto consulta, mas só conversar, desabafar... E essa questão social toda, se a pessoa tem trabalho, renda, lazer, se tá na escola. Tanto criança, como os idosos que também tão procurando muito. Um dos maiores problemas que a gente percebe são problemas sociais mesmo, assim, familiar, questão de álcool, drogas e problema conjugal.

Essa noção de cuidado permite uma aproximação à ideia de produção social da saúde, quando se percebe que o modo de vida, o modo de pensar e as condições sociais das pessoas devem ser considerados pelos profissionais, o que é proposto por Escorel e colaboradores (2007). Portanto, reafirma-se a importância de uma postura diferenciada da equipe conforme observado na categoria anterior, embora agora seja evidenciado que esta nova postura deva ser traduzida em mudanças na forma de fazer saúde dos profissionais, a partir da implementação de ações orientadas pelas necessidades percebidas, de aspectos biológicos e psicossociais. Desta forma, percebe-se uma representação de cuidado coerente com o que afirmam Maia e Vaghetti (2008). A preocupação com a prosperidade das famílias passa a ser propósito do cuidado, e este é compartilhado com os próprios usuários, o que evidencia quão ampla deve ser a abordagem das equipes em seus territórios, sendo o cuidado construído a partir das diferentes realidades.
Entretanto, a atuação dos profissionais ainda não atinge o nível macro, ou coletivo, pois embora haja preocupação com os determinantes sociais e seus efeitos sobre a situação de saúde das famílias, não é perceptível a construção de mecanismos de mudanças da realidade coletiva, e deste modo a ação de cuidado parece não alcançar a potencialidade de habilitar os sujeitos a engendrar novos arranjos sociais num cenário de cidadania, conforme defendem Pinheiro e Guizardi (2008). Portanto, embora o desenvolvimento de habilidades pessoais represente um avanço no cuidado, identifica-se limites em relação à implementação de práticas de promoção da saúde, uma vez que a ação intersetorial no âmbito do território, que deve ser necessariamente política, ainda se mostra limitada a demandas específicas dos sujeitos e de suas famílias.

Esta categoria também pode ser observada no DSC construído a partir das falas dos gestores locais:

A atenção básica é extremamente complexa... Sóque ela trabalha com tecnologias leves. Então, assim... a complexidade social, dinâmica social, dependendo do território que vocêtrabalha. Eu não sou enfermeira por caridade. Então, profissionalmente falando, a responsabilidade, o comprometimento que vocêtem que ter pra se dispor a cuidar de alguém não éfácil, não é qualquer relação que você estabelece. Na UTI, a sensação que a gente tem é que a gente fica guardadinho lá, né? E aqui chega um paciente, aí ele tá estressado porque ele quer só trocar o cartão, evocê tá tentando explicar pra ele que não dá. Aí eu respiro fundo, Deus do céu. Então, se acontece comigo ia pararna delegacia. Então são situações que não são fáceis de você lidar... vai... do grau de instrução da comunidade, até do próprio entendimento que eles têm da Estratégia, do Centro de Saúde...

O DSC dos gestores, além de corroborar o que disseram os trabalhadores, revela a dificuldade sentida pela equipe em lidar com as singularidades dos sujeitos, que são mais perceptíveis quando em um serviço de saúde territorializado. De alguma forma as necessidades da população são percebidas e demandam uma resposta da equipe, que nem sempre se sente apta a acolhê-las ou capacitada para lidar com situações de cobrança dos usuários.

Esta questão evidencia os limites do processo de 
trabalho da Saúde da Família, que carece de suporte para dar conta não apenas da demanda expressa em quantidade de procedimentos individuais e coletivos a serem realizados, mas, sobretudo, da complexidade envolvida nos diferentes problemas de saúde. Estes são atravessados por questões sociais e subjetivas que requerem uma prática interdisciplinar ampliada e o suporte de uma rede de serviços especializados, de forma a potencializar o cuidado no território.

Evidencia-se aqui a relevância do aspecto político em relação à necessidade de se estabelecer maneiras concretas de se integrar práticas e serviços de saúde, bem como do aspecto interrelacional, do encontro de sujeitos característico da ESF, que aparenta ser algo ainda difícil e que tem sua importância no estabelecimento da ação cuidadora. Para ela, segundo Heimann e Mendonça (2005), é preciso que os profissionais desenvolvam uma nova abordagem, baseada numa interação qualificada da equipe que oriente os serviços para as comunidades em que habitam as famílias, evitando uma relação pautada na verticalidade.

\section{Cuidado como articulação de ações interdiscipli- nares de prevenção, promoção e tratamento, que visem qualidade de vida}

Nesta categoria nota-se que o cuidado também se relaciona com a noção de integralidade das ações de saúde, ao referirem prevenção, promoção e tratamento, corroborando o que é proposto enquanto princípio do SUS (Brasil, 1990). Esta ampliação do olhar sobre os problemas de saúde é observada no discurso dos gestores:

Trabalhar junto com a pessoa com foco na qualidade de vida. É claro que quando a pessoa está doente o nosso foco é tentar a cura, não é? Ela faz parte da atenção básica também... mas eu acredito que a cura é só uma parte pequena de todo o processo de cuidado. Quando você vai para a atenção primária, sua visão é totalmente descortinada, você vê o paciente como um todo... abre um leque de cuidado na vida com relação à qualidade de vida, à promoção, à prevenção. Você vê o ser humano, é... no total, familiar, no ambiente.

A Atenção Primária é entendida como estratégica para a construção de um processo de cuidado amplo e contextualizado, por deixar evidenciado aos olhos dos profissionais a complexidade envolvida nos diferentes problemas de saúde.

Esta complexidade demanda ações da equipe na perspectiva da qualidade de vida. Assim, as ações de cuidado são realizadas no contexto de consultas, exames ou grupos, a exemplo dos grupos de hipertensos e de gestantes, conforme pode ser observado no fragmento do DSC:

Vendo o problema, eu faço o agendamento na casa pra pessoa de uma consulta, marco um exame, faço encontros de grupos de hipertensos, de gestante. Pra mim o cuidado envolve todas as pessoas da família e ébem integral, tanto com questão ao tratamento de doenças, prevenção e promoção de saúde, qualidade de vida. Nessa visão integral, deve-se trabalhar com outros profissionais da saúde que possam complementar e adicionar conhecimentos das diversas áreas. Eu acho que é impossível o ser humano conhecer tudo e era tudo muito focado no médico.

Percebe-se que a qualidade de vida é relacionada à busca de bem-estar diante de um problema, geralmente uma questão biológica patológica ou natural. Esta é a base para o entendimento que a equipe tem sobre promoção da saúde, o que deve ser revisto. Neste contexto, a interdisciplinaridade é entendida como condição para exercer o cuidado, o que é um avanço na abordagem de demandas biológicas, embora insuficiente quando se busca a integralidade:ao demonstrar um excessivo foco no ato profissional, restringe o cuidado à intervenção da equipe e a seus conhecimentos de ordem técnica, não havendo referência a um processo necessário de participação e exercício de autonomia da população, que configuraria um cuidado participativo. Assim, percebe-se um limite quanto à inserção das diversas aspirações por saúde possíveis (Ayres, 200o) no âmbito da ESF, o que restringe ou simplifica essa busca pela qualidade de vida.

O fragmento abaixo também explicita esta ideia:

O processo de doença não está relacionado só com o indivíduo, e nem só num órgão. Eu acho que a doença vai além do que isso, então geralmente não é só um foco orgânico, por exemplo, uma dor no es. tômago, eu não posso pesquisar só gastrite, eu vou 
procurar onde aquela pessoa tá inserida, a família dela, procuro ver problemas na família, problemas no trabalho dela. Trabalhar não só em cima da doença em si. Tentar de toda forma ajudarno problema que possa estar levando a essa doença física.

Este discurso demonstra a contradição vigente no processo de trabalho da equipe, que associa a noção de bem-estar e qualidade de vida a uma situação de doença: embora o olhar sobre esta doença seja ampliado, o cuidado é necessariamente vinculado a um processo patológico, com ações focadas tanto na doença quanto nos fatores que a ocasionam. Aqui, o cuidado é voltado para aqueles que vivenciam alguma situação de sofrimento, ou de vulnerabilidade, e que apresentam um sintoma físico, sendo estas as pessoas a serem cuidadas pela equipe. Essa noção de sofrimento apontada não parece funcionar como importante categoria central no entendimento de integralidade do cuidado em saúde, pois foca-se na doença física, e segundo Camargo Jr. (2007), isso demonstra o resquício de uma medicina tecnobiomédica, que deve ser superada.

Essa centralidade na doença evidencia também uma noção de multicausalidade dos problemas de saúde que deve ser superada, sendo necessário rever as práticas dos profissionais e reorganizar os processos de trabalho, conforme afirmam Heimann e Mendonça (2005). A ideia de determinação social do processo saúde-doença deve orientar o trabalho da equipe, embora isto ainda não aconteça na realidade estudada, contrariando Giovanella (2008) que afirma ser esta a concepção que deve orientar o modelo assistencial na Atenção Primária.

O foco na doença também é observado quando a equipe deixa transparecer um excessivo privilégio de ações de prevenção em seu discurso:

Cuidar da saúde é qualidade de vida, é prevenir, orientar a família a ter cuidados com ela, com a sua família, higienização bucal, alimentação... é também exercícios que ela tem que fazer, fazer exames, ter consultas, né?

Neste discurso, fica notória a relação do cuidado com estilos e hábitos de vida, que devem ser orientados e acompanhados pela equipe, numa perspectiva preventivista que entende qualidade de vida como ausência de doença. Cuidar, portanto, é evitar que uma doença se instale, contrariando Ayres (2001), que afirma que cuidar é mais que construir um objeto e intervir sobre ele, devendo-se superar a fragmentação das ações de saúde. Desta forma, entender que o cuidado só é possível quando se protege ou evita o adoecimento das pessoas, reflete uma perspectiva reducionista, que segundo Mattos (2009) deve ser problematizada.

Uma vez discutidas as representações de cuidado apreendidas no discurso da equipe, revela-se a seguir as Ideias Centrais percebidas referentes à integralidade do cuidado.

\section{Autonomia profissional, criação de vínculos de confiança e responsabilização pelas pessoas, inserindo-as em todas as ações da equipe}

Esta categoria demonstra que a representação de integralidade do cuidado passa pelo vínculo estabelecido entre profissionais e usuários, com especial participação do agente comunitário de saúde. Este vínculo propicia maior responsabilização dos profissionais pelos problemas enfrentados pelas pessoas e aponta para uma integração usuário-equipe, a partir da ideia de compartilhamento de experiências e subjetividades. Tal constatação corrobora Pinho e colaboradores (2007), que afirmam que a subjetividade no cuidado integral relaciona-se à compreensão da natureza do ser por inteiro, redimensionando os serviços, a partir do acolhimento e do vínculo. 0 fragmento abaixo ilustra tal achado:

...fazer um bem para a comunidade, para as pessoas... está ali ajudando a pessoa, está satisfazendo, conseguindo o que quer... É sentir na pele, não é... ir lá e vestir a camisa do Agente de Saúde, da comunidade, você está vestindo a saúde... levando a saúde para a comunidade. Eles se tornam sua família porque você não visita somente para saber como é que ele está,você visita também para convidá-lo pra um grupo, para fazer uma participação de tudo, das consultas, em geral... fazer parte da nossa equipe... você tem todo um cuidado de promoção, de prevenção. Às vezes ela quer simplesmente conversar com a gente, então isso também faz parte da saúde... $\varepsilon$ aí quando ela conversa com você, ela fica bem. Às vezes ela tem dúvida, num está muito bem...

Este redimensionamento permite a implemen- 
tação de diferentes ações de prevenção, promoção e de tratamento, o que reforça a constatação de que as práticas no âmbito da ESF devem ser diversificadas e orientadas para as diferentes necessidades de saúde. Esta integralidade de ações, potencializada pela valorização da responsabilização, do acolhimento e do vínculo na prática da equipe, permite o desenvolvimento de práticas integrais, sobretudo quando o usuário é colocado como sujeito de sua própria história, corroborando o que defendem Gomes e Pinheiro (2005).

Se a busca pela integralidade de ações é mencionada, percebe-se que esta ainda se dá em um contexto onde as ações de prevenção são privilegiadas, conforme pode ser observado no fragmento a seguir:

$\varepsilon$ a prevenção primeiro. Você está junto daquele paciente, a integralidade não é cuidar a doença, é prevenir essa doença, a saúde é mais controlada, assim, num todo. $\varepsilon$ você saber a realidade desse paciente, mais ou menos, em que você pode prevenir essa doença. Não precisa o paciente estar doente pra você estar cuidando dele.

Embora seja evidenciada uma preocupação com o contexto dos usuários, este é considerado como estratégico para a prevenção de problemas de saúde, transparecendo o predomínio de uma perspectiva higienista de controle, que não entende a relação entre saúde e doença como processual, evidenciando mais uma vez a dificuldade da equipe em integrar as ações em seu território.

De forma geral, esta categoria articula as representações sobre o cuidado demonstradas na questão anterior. Ou seja, está intrinsecamente ligada a uma postura considerada atributo da equipe, à responsabilização e à articulação de diferentes ações em consonância com as necessidades de saúde percebidas.

Esta Ideia Central também é percebida no discurso dos gestores locais, que revela também o papel da autonomia da equipe na realização de ações de cuidado integral junto às famílias:

Pré-natal, por exemplo, pegando um resultado de urina alterado, paciente com queixa... a gente já colocou um protocolo. Hoje você sabendo que esse paciente tá lá cheio de verminose... você pode fazer desde orientação à prescrição da medicação... a fazer uma visita na casa dele e... olha, vamos fazer assim, vamos fazer assado... lavar a mão, orienta na escola, né? Então a gente tem uma autonomia muito maior que em outras situações você não tem. Eu quero ficar no PSF pela questão da integralidade e da autonomia no Saúde da Família. Porque fui enfermeira de terapia intensiva, de UTI neonatal, e tudo tinha que pedir para o médico...

Ressalta-se a importância da governabilidade da equipe na abordagem das necessidades de saúde da população, que demandam tanto a execução de ações programadas quanto espontâneas, ampliando a dimensão das práticas conduzidas na Atenção Primária. Ou seja, é na percepção do sofrimento do sujeito e da busca deste por formas específicas de cuidado que se dá a coprodução da demanda e da oferta, caracterizando a atenção à saúde naquele instante, conforme afirma Camargo Jr (2007). Isto fica evidente quando é feita a comparação com o ambiente hospitalar, que apresenta protocolos e rotinas mais rígidos, considerado pela equipe um local menos susceptível às mudanças constantes.

Esta representação de integralidade do cuidado demonstra que a equipe percebe os problemas sob a ótica do trabalho em equipe, e mesmo em situações em que o vínculo do usuário é estabelecido com um profissional específico, este se sente apto a conduzir uma situação, por saber que há uma retaguarda da equipe. Esta retaguarda pode ser concretizada por meio do estabelecimento de protocolos e rotinas, que são pactuações que cada equipe constrói para lidar com sua realidade. A partir de dados da observação foi possível perceber como os profissionais organizavam suas ações, que rompiam com as restrições dos campos de prática profissional, a partir de uma postura que compartilhava saber e práticas, fundamentando assim um campo interdisciplinar. Isto demonstra que cuidar integralmente relaciona-se com competências e tarefas técnicas, mas vai além, corroborando Ayres (2001).

\section{Sujeito visto como um todo, considerando o contexto geral da família na determinação e no enfrentamento dos problemas}

Esta categoria explicita a representação da equipe que vincula integralidade do cuidado à noção de indivisibilidade do sujeito, que é visto como um todo. 
A proposta de atuação generalista das equipes de saúde da família parece contribuir para que as pessoas não sejam vistas sob o olhar das especialidades, mas que estas se complementem e possam expressar a situação de saúde apreendida pela equipe. Ao considerar o sujeito em seu contexto, questões de ordem moral e espiritual são inseridas e consideradas no processo de cuidar e no entendimento do que é saúde e doença para os usuários, embora não esteja explícito como se dá a relação de tais questões no contato cotidiano com as famílias e como este terreno marcado por diversidades é compreendido pela equipe de saúde.

Cuidado integral é a pessoa estar bem fisicamente, psicologicamente, mentalmente, espiritual... e moralmente. $\varepsilon$ cuidar da pessoa como um todo. Não podemos hoje separar o cardíaco, o hipertenso, o diabético, você tem que ver o paciente, a família como um todo. A gente não cuida só do estômago da pessoa.

Não obstante, percebe-se uma aproximação da representação de integralidade do cuidado à ideia de cuidado defendida por Maia e Vaguetti (2008), embasando escolhas e decisões dos diferentes sujeitos. Neste debate, ao considerar o ser humano como indivisível, e o cuidado como contextualizado, a equipe deve evitar atender às necessidades dos sujeitos em sua totalidade, o que poderia ocasionar a negação da autonomia e uma medicalização integral, conforme sinaliza Camargo Jr. (2007).

A ampliação do olhar para o contexto das famílias pode ser percebida no fragmento abaixo:

Ver se a criança tá na escola, se a pessoa tem renda, o habitat, lazer, se tá emocionalmente bem, as tensões emocionais e as relações interpessoais, até mesmo com a vizinhança. A saúde social, a questão de trabalho, das pessoas que convivem ao redor dela, você sente aquele impacto da parte social, econômica, né... tendo todo aquele conceito amplo agora de saúde, a pessoa consegue pelo menos amenizar seus problemas, então... todos os setores, saúde, educação... integrados no cuidado das questões que mais acometem a população. Engloba também a intersetorialidade com os outros órgãos do governo, e comunidade, associações, ONGs. Você tem uma visão mais holística da coisa.
A equipe considera o contexto familiar e social dos usuários, abordando os determinantes sociais do processo saúde-doença que determinam a heterogeneidade das condições de vida e da situação epidemiológica da população. Para tanto, entende que as práticas de integralidade do cuidado devem ser construídas em parceria com outros setores da sociedade, não apenas envolvendo outros integrantes da família. Evidencia-se neste discurso a noção de integralidade do cuidado em relação às diversas necessidades das famílias, sendo os problemas de saúde apenas parte delas, e assim a situação geral da família torna-se objeto de preocupação dos profissionais.

Na questão anterior, observou-se uma tendência da equipe a simplificar ações de promoção, inserindo-as num contexto de processos biológicos ou patológicos. Aqui, quando situado numa perspectiva de integralidade, observa-se uma aproximação ao que Machado e colaboradores (2007) apontam como fundamental, que é perceber o usuário como sujeito histórico, social e político, articulado ao contexto familiar, ao meio ambiente e à sociedade na qual se insere. Assim, percebe-se uma contradição da equipe em relação à ampliação de suas práticas, o que, no contexto político-gerencial da saúde do Distrito Federal, pode evidenciar um importante processo de transformação do modelo assistencial.

Nota-se também que as ações de cuidado passam a demandar uma organização coletiva, que não se restringem à equipe, mas que dependem de uma postura diferenciada dela, por vezes protagonista, coincidindo com a definição de integralidade ampliada proposta por Cecílio (2009). A integralidade do cuidado parece relacionar-se com a dimensão política apontada por Mattos (2009), à medida que se opõe ao processo de redução dos sujeitos a objetos descontextualizados, demandando, portanto, um cuidado intersetorial. Assim, os serviços devem interagir com outros setores sociais para intervir nas desigualdades entre os grupos humanos.

No DSC dos gestores locais, a preocupação com as questões familiares e sociais também é parte da representação destes sujeitos em relação à integralidade do cuidado, como se observa a seguir:

Você viu além da doença, viu o social, o emocional, então a partir desse momento foi estabelecido um 
cuidado integral. Por exemplo, uma paciente grávida que não fazia os exames. Eu já ia chegar e dar uma bronca nela, mas resolvi na hora me segurar e perguntar o que aconteceu. E aí ela chorou e falou que não queria a gravidez, pois o marido a abandonou assim que engravidou e saiu com outra. Então, eu fui além. Outro caso, um senhor foi atropelado por um caminhão, e a preocupação dele era que ele tava sem trabalhar. Ele nervoso, angustiado, e respondia mal a mulher dele. Um transtorno no serviço... E aí a gente parou pra conversar. Ele não tem benefício... e tem os filhos pra sustentar, né? Então, a gente faz os diagnósticos de enfermagem, tudo... mas não deve ser só o diagnóstico de padrão respiratório alterado. $\varepsilon$ o problema social?

Percebe-se no fragmento acima a importância de se transformar a relação com o usuário, qualificando a escuta, corroborando Cecílio (2009), o que traz importantes reflexos nas práticas de educação em saúde, que passam a visar a autonomia e a emancipação para o cuidar de si, conforme afirmam Machado e colaboradores (2007). Esta experiência foi relatada pela equipe, que entendeu que ir além da conduta sobre um diagnóstico representa uma necessidade para se cuidar integralmente. Há, portanto, uma aproximação à clínica humanizada possibilitada pela escuta acolhedora dos sofrimentos, e que integra dimensões físicas, psíquicas e sociais, permitindo um cuidado integral, fortalecendo a autoestima e a criação de espaços afetivos, de autonomia e de vida saudável, conforme postulam Silva Jr e colaboradores (2007) e Camargo Jr (2007).

\section{Integração da ESF com demais Serviços do Sistema}

A noção de integração do sistema e dos serviços de saúde em geral, do estabelecimento de relações institucionais tanto com equipamentos do mesmo nível de atenção quanto com outros níveis do sistema, demonstra uma perspectiva de cuidado em rede como parte do conceito de integralidade do cuidado. Esta noção também demonstra a necessidade de se articular diferentes práticas e conhecimentos, e considera que há limites para a resolução dos problemas de saúde no âmbito da ESF. Entretanto, este discurso não revela qual seria o papel da equipe na organização dessa integração, pois embora haja uma responsabilização pelo problema de saúde do usuário, serão demandadas práticas que vão além da simples realização de encaminhamentos, como caracteriza a equipe no fragmento abaixo:

Ter uma integração assim, por exemplo, PSF com os hospitais, com os postos de saúde, com as outras unidades de saúde... né? Se eu num posso resolver o problema agora, aqui, eu posso indicar pra ela procurar um outro órgão, um outro lugar que ela possa resolver o problema dela.

E se a equipe entende ser importante construir a integralidade do cuidado a partir da integralidade dos serviços, deverá, pois, assumir a responsabilidade por organizar o sistema e coordenar suas ações, estabelecendo novas formas de comunicação e compartilhamento de responsabilidades, conforme propõem Starfield (2004) e Giovanella (2008). Assim, a Atenção Primária, enquanto centro de comunicação do sistema (Brasil, 2010), deve buscar redefinir seus processos de trabalho, o que ainda se mostra incipiente na realidade observada.

Algumas ações isoladas demonstram que a equipe tem tentado articular uma maior aproximação com outros serviços, a exemplo do hospital:

... eu tento pelo menos não trazer tudo muito pro enfermeiro... porque se a gente fizer tudo, a gente não dá conta. Então vamos na assistente social, lá no hospital, lá são três por andar... Vamos ver o que a gente pode fazer, né? Ela vai orientar a gente de alguma forma. Então assim... pra gente também não levar tudo... porque senão você leva aquela carga, daqui a pouco você vai fazendo vaquinha pra todos os pacientes...

Embora esta busca por outros profissionais, exemplificada pela figura do assistente social no hospital, demonstre a implicação da equipe na busca de solução para os problemas, aponta também a dificuldade em estabelecer uma rede organizada e pactuada. A rede é caracterizada como precária, pois neste exemplo o profissional é funcionário do hospital e deveria atender apenas casos internos. Ademais, chama atenção a falta de referência ao sistema de regulação e seu papel na construção da integralidade do cuidado: não há garantia de tratamento às pessoas que necessitam, sendo que o 
impacto da regulação na garantia da integralidade do cuidado e na consolidação da ESF deve ser objeto de novas investigações científicas.

Logo, não há uma transformação substantiva da lógica organizativa dos serviços e sistemas locais de saúde, o que, de acordo com Sousa e MerchanHamann (2009), faz com que haja um predomínio do modelo clássico de assistência a doenças que deve ser superado com vistas à consolidação de uma proposta orientada pela integralidade do cuidado.

\section{Apontamentos para o Fortalecimento da Integralidade do Cuidado na ESF}

Os achados evidenciam algumas questões que subsidiam o processo de consolidação da Estratégia Saúde da Família no Distrito Federal.É possível perceber que a responsabilização da equipe pelo bem-estar da população, mediante uma postura sensível aos problemas, permite maior vinculação com os usuários, potencializando o contínuo processo de reorientação das práticas de saúde a partir da produção de intersubjetividades. As diferentes necessidades das famílias são objeto de preocupação da equipe, que considera os aspectos biológicos, psíquicos e sociais na determinação da saúde e da doença. Entretanto, embora o contexto social seja entendido como relevante no cuidado, as ações ditas promotoras de saúde não estão articuladas ao nível macro das relações. Isso é especialmente relevante em situações nas quais há demanda biológica explícita. Embora o contexto social seja considerado na compreensão dos problemas, ainda não há ações intersetoriais planejadas e executadas pelas equipes.

Diante dessa característica paradoxal, faz-se necessário que a concepção de multicausalidade dos problemas de saúde dê lugar ao entendimento da determinação do processo saúde-doença-cuidado, o que representa uma necessária ampliação do olhar e do fazer acerca dos problemas de saúde, considerando-se a posição central que a prevenção ocupa nas representações de integralidade do cuidado dos profissionais, que devem avançar em direção à Promoção da Saúde.
Finalmente, verificou-se que a integração com uma rede de outros serviços é fundamental para que as ações de cuidado possam ter continuidade, o que precisa ser entendido e coordenado pela equipe a partir de uma ação protagonista, bem como viabilizado por meio da efetivação de políticas públicas.

Assim, a integralidade do cuidado é percebida como um objetivo da equipe, e para tanto, estudos que aprofundem as ações envolvidas neste processo se fazem necessários. Sem a pretensão de quantificar o conhecimento aqui produzido, sugere-se maior atenção dos gestores e profissionais em relação às ações promotoras de saúde conduzidas no âmbito do território.

\section{Referências}

AYRES, J. R. C. M. Cuidado: tecnologia ou sabedoria prática. Interface - Comunicação, Saúde e Educação, Botucatu, v. 4, n. 6, p. 117-120, 2000.

AYRES, J. R. C. M. Sujeito, intersubjetividade e práticas de saúde. Ciência e Saúde Coletiva, Rio de Janeiro, v. 6, n. 1, p. 63-72, 2001.

BRASIL. Lei nº 8o80, de 19 de setembro de 1990. Dispõe sobre as condições para a promoção, proteção e recuperação da saúde, a organização e o funcionamento dos serviços correspondentes e dá outras providências. Diário Oficial da União, Brasília, DF, 19 set. 1990. Seção 1, p. 18055.

BRASIL. Conselho Nacional de Secretários de Saúde. Atenção primária e promoção da saúde. Brasília, DF, 2007.

BRASIL. Ministério da Saúde. Portaria no 4279 , de 30 de dezembro de 2010. Estabelece diretrizes para a Rede de Atenção à Saúde. Diário Oficial da União, Brasília, DF, 30 dez. 2010. Seção 1, p. 89.

CAMARGO JR, K. R. Um ensaio sobre a (in) definição de integralidade. In: PINHEIRO, R.; MATTOS, R. A. (Org.). Construção da integralidade: cotidianos, saberes e práticas em saúde. Rio de Janeiro: UERJ, IMS: Abrasco, 2007. p. $37-46$. 
CECÍlLIO, L. C. E. As necessidades de saúde como conceito estruturante na luta pela integralidade e equidade na atenção em saúde. In: PINHEIRO, R.; MATTOS, R. A. Os sentidos da integralidade na atenção e no cuidado à saúde. Rio de Janeiro: UERJ, IMS: Abrasco, 2009. p. 117-130.

COSTA, A. M. Integralidade na atenção e no cuidado a saúde. Saúde e Sociedade, São Paulo, v. 13, n. 3, p. 5-15, 2004.

DISTRITO FEDERAL. Secretaria de Estado de Saúde. Plano Diretor de Regionalização do Distrito Federal PDR/DF. Brasília, DF, 2007.

DISTRITO FEDERAL. Secretaria de Estado de Saúde. Relatório Estatístico da SES e HUB. Brasília, DF, 2011.

ESCOREL, S. et al. O Programa de Saúde da Família e a construção de um novo modelo para a atenção básica no Brasil. Revista Panamericana Salud Pública, Washington, DC, v. 21, n. 2/3, p. 164176, 2007.

GIOVANELLA, L. Atenção primária à saúde seletiva ou abrangente? Cadernos de Saúde Pública, Rio de Janeiro, v. 24, p. 21-23, 2008. Suplemento 1.

GOMES, M. C. A.; PINHEIRO, R. Acolhimento e vínculo: práticas de integralidade na gestão do cuidado em saúde em grandes centros urbanos. Interface - Comunicação, Saúde, Educação, Botucatu, v. 9, n. 17, p. 287-301, 2005.

HEIMANN, L. S.; MENDONÇA, M. H. A trajetória da atenção básica em saúde e do Programa de Saúde da Família no SUS: uma busca de identidade. In: LIMA, N. T. et al . Saúde e democracia: história e perspectivas do SUS. Rio de Janeiro: Fiocruz, 2005. p. 481-502.

LEFÉVRE, F.; LEFÉVRE, A. M. C. O discurso do sujeito coletivo: um novo enfoque em pesquisa qualitativa (desdobramentos). Caxias do Sul: EDUCS, 2003.

MACHADO, M. F. A. S. et al. Integralidade, formação de saúde, educação em saúde e as propostas do SUS: uma revisão conceitual. Ciência \& Saúde Coletiva, Rio de Janeiro, v. 12, n. 2, p. 335-342, 2007.
MAIA, A. R.; VAGHETTI, H. H. O cuidado humano revelado como acontecimento histórico e filosófico. In: SOUSA, F. G. M.; KOERICH, M. S. (Org.). Cuidar - cuidado: reflexões contemporâneas. Florianópolis: Papa-Livro, 2008. p. 15-33.

MATTOS, R. A. Os sentidos da integralidade: algumas reflexões acerca de valores que merecem ser defendidos. In: PINHEIRO, R.; MATTOS, R.

A. Os sentidos da integralidade na atenção $e$ no cuidado à saúde. Rio de Janeiro: UERJ, IMS: Abrasco, 2009. p. 43-68.

MENDONÇA, M. H. M.; VASCONCELLOS, M. M.; VIANA, A. L. A. Atenção primária à saúde no Brasil. Cadernos de Saúde Pública, Rio de Janeiro, v. 24, p. s4-s5, 2008. Suplemento 1.

MERHY, E. E. Um ensaio sobre o médico e suas valises tecnológicas: contribuições para compreender as reestruturações produtivas do setor saúde. Interface - Comunicação, Saúde, Educação, Botucatu, v. 4, n. 6, p. 109-116, 2000.

PINHEIRO, R.; GUIZARDI, F. L. Quando dádiva se transforma em saúde: algumas questões sobre a integralidade e o cuidado nas relações entre sociedade e Estado. In: PINHEIRO, R.; MATTOS, R. A. (Org.). Cuidado: as fronteiras da integralidade. Rio de Janeiro: UERJ, CEPESC: Abrasco, 2008. p. 39-58.

PINHO, L. B. et al. A integralidade no cuidado em saúde: um resgate de parte da produção científica da área. Revista Eletrônica de Enfermagem, Goiânia, v. 9, n. 3, p. 835-846, 2007. Disponível em: <http://www.fen.ufg.br/fen_revista/vg/n3/pdf/ vgnza22.pdf $>$. Acesso em: 27 out. 2010.

SANTOS, M. F. S. Representações sociais e psicologia social. In: ALMEIDA, A. M. O.; JODELET, D. Representações sociais: interdisciplinaridade e diversidade de paradigmas. Brasília, DF:

Thesaurus, 2009. p. 51-62.

SILVA JR, A. G.; MERHY, E. E.; CARVALHO, L. C. Refletindo sobre o ato de cuidar da saúde. In: PINHEIRO, R.; MATTOS, R. A. (Org.). Construção da integralidade: cotidiano, saberes e práticas em saúde. Rio de Janeiro: UERJ, IMS: Abrasco, 2007. p. 115-130. 
SOUSA, M. F. O Programa Saúde da Família no

Brasil: análise do acesso à atenção básica. Revista

Brasileira de Enfermagem, Brasília, DF, v. 61, n.

2, p. 153-158, 2008.

SOUSA, M. F.; MERCHAN-HAMANN, E. Saúde da família no Brasil: estratégia de superação da desigualdade na saúde? Physis, Rio de Janeiro, v. 19, n. 3, p. 711-729, 2009.

STARFIELD, B. Atenção primária, equilibrio entre necessidades de saúde, serviços e tecnologia.

Brasília, DF: Unesco: Ministério da Saúde, 2004.

Recebido em: 15/04/2011

Reapresentado em: 23/10/2012

Aprovado em: 23/11/2012 